\title{
CORRECTION
}

\section{Correction to: Blockchain in travel}

\section{B. Vinod ${ }^{1}$}

Published online: 21 November 2019

c) Springer Nature Limited 2019

\section{Correction to: Journal of Revenue and Pricing Management https://doi.org/10.1057/s41272-019-00213-6}

The author would like to correct the errors in the publication of the original article. The corrected details are given below for your reading.

In Introduction section, sixth sentence of the second paragraph should read as:
Information can only be appended with consensus from all parties in the blockchain.

Publisher's Note Springer Nature remains neutral with regard to jurisdictional claims in published maps and institutional affiliations.

The original article can be found online at https://doi.org/10.1057/ s41272-019-00213-6.

B. Vinod

benvinod@yahoo.com; ben.vinod@sabre.com

1 Sabre, Southlake, USA 